\title{
Audit on Enterprises' Environmental Cost from the Perspective of Low-Carbon Economy
}

\author{
Mei Wu \\ Zhengzhou Railway Vocational and Technical College, Zhengzhou, 450052, China
}

Keywords: Low-carbon economy. Environmental cost of enterprises. Cost audit

\begin{abstract}
In order to realize low-carbon economic development, Chinese government has transmitted goals of energy conservation and emission reduction to all local governments. It is essential to enhance audit on enterprises' environmental cost to realize real low-carbon economy. Low-carbon economy and audit on enterprises' environmental cost are premise of each other and supplement each other. Via theoretical application of low-carbon economy to audit on enterprises' environmental cost, enterprises' risk of environmental damage can be reduced fundamentally. At the same time, supervision of the outside on audit on enterprises' environmental cost can also be strengthened. This thesis will mainly focus on analyzing current situations and necessity of environmental cost audit in low-carbon economy and propose methods by which audit on enterprises' environmental cost can be implemented.
\end{abstract}

\section{Introduction}

Subject with high carbon emission are enterprises in China, so it is quite necessary to enhance audit on enterprises' environmental cost. If we want to drive our low-carbon economic development, it will be essential to improve enterprises' environmental protection input and strengthen enterprises' control of environmental cost. Meanwhile, under new economic policies, enterprises must enhance management of environment if they want to achieve further development. Especially, estimation on environmental cost should run through enterprises' decisions and activities. With policy support of the country, realization of enterprises' favorable environmental management can not only help them reduce environmental cost but also change enterprises' development mode from extensive one to intensive one and realize enterprises' sustainable development. As enterprises' environmental cost is an important link of enterprises' cost system management, enhancement of environmental cost audit may strengthen environmental cost control effectively and make low-carbon production possible.

\section{Introduction to low-carbon economy and audit on enterprises' environmental cost}

In accordance with related economic theory, it is found that low-carbon economy is a new economic development mode that is proposed to cope with increasingly severe climatic and environmental problems in the 21st century. Being guided by idea of sustainable development, low-carbon economy mainly uses methods like innovative techniques and new energy to reduce consumption of carbon energy in the production process as much possible. In addition, low-carbon economy mainly aims at creating a win-win situation of economic development and environmental protection. It is the energy white paper of British government that represents low-carbon economy enters the public's view by the image governmental document. According to the energy white paper, it is shown that low-carbon economy improves usage rate of resources and environmental protection ratio as much as possible when it directs at maximizing economic benefits. Reduction in pollution helps with environment optimization, and environment optimization is helpful for people to improve our living standard and quality. In low-carbon economy, its core lies in how to use resources efficiently, cleanly and circularly and follow three-low emission principle. All kinds from production to consumption improve resource utilization rate, by which sustainable development of economy can be driven. 
Up to now, there has been no uniform concept defining environmental cost. Besides, related final verdicts in the aspects of content and classification are also lacked. However, according to definitions that related international organizations give to environmental cost, environmental cost refers to additional expenditure caused by enterprises' attempt to reduce negative effect of producing activities on environment. In accordance with classification offered by related foreign departments, environmental cost is divided into environmental-affair cost and cost resulted from elimination of environmental pollution and environmental loss. Based on traditional definitions of cost, we may simply define environmental cost as all expenditures that are generated by enterprises in production to prevent and solve environmental problems. This kind of expenditures contains losses caused by environmental pollution.

Audit on enterprises' environmental cost refers to auditing work on expenditures of enterprises' environmental cost. Via audit, cost control can be realized from the beginning of producing activities to final sales. According to auditing results, we can know effect of enterprises' low-carbon production. Based on current cost, audit on enterprises' environmental cost estimates environmental cost after production. At the same time, cost audit not only directs at enterprises' internal environmental cost but also must contain external environmental cost of enterprises. Via auditing work, environmental cost can be estimated well before production and conclusions about environmental pollution in the production process may be drawn after finishing production, which provides convenience for future improvement in work.

\section{Necessity of enterprises' implementation of environmental cost audit in low-carbon economy}

Environmental cost audit can promote low-carbon economic development effectively. In accordance with current international situations, it is easy to foresee that low-carbon economy is an inevitable trend of human economic development in future. Under the situation that total energy is limited, low-energy and low-emission economic development model can realize the goal of sustainable economic development for people. In consideration of this, an increasing number of countries begin to advocate domestic enterprises realize low-carbon economic development model energetically. China also proposes the task 'energy conservation and emission reduction' in 'the 11th Five-year Plan’ planning outline. Main purpose of 'energy conservation and emission reduction' is to drive readjustment of our industrial structure, promote upgrade of traditional industries via policy support and improve proportion of high-tech enterprises in industry.

Under the condition that low-carbon economy becomes mainstream thought, audit on enterprises' environmental cost is helpful for our country to drive economic development, realize low carbon and achievement goals of energy conservation and emission reduction. Thus, it is quite essential to strengthen audit on enterprises' environmental cost, especially the environmental cost audit dominated by the government. The environmental cost audit dominated by the government is featured by authority and coerciveness, so it can help enterprises completely change their management ideas better, drive enterprises to realize low carbon in operation directions and modes and supervise and urge enterprises to realize all-dimensional low carbon in their production and operation.

\section{Main points of audit on enterprises' environmental cost at present}

In order to carry out audit on enterprises' environmental cost better, we need center on key points to implement production links and environmental cost. If we carry out comprehensive audit of environmental cost, workload will be too large. Additionally, it is no need to do so. Audit emphases are mainly reflected in the following aspects.

\section{Whether environmental cost accounting of enterprises is true or not}

Authenticity of audit on enterprises' environmental cost is mainly reflected by whether enterprises' reports on environmental cost are true or not. Key points of authentic auditing work mainly include the following aspects. 
1). Strengthen audit on enterprises' activities related to environmental protection. To publicize and improve enterprise images, enterprises are amenable to report situations like environmental objectives and environmental management of enterprises to stakeholders in the process of production and management. At the same time, enterprises should publish amount of their expenditures resulted from pollution control and environmental enhancement to the society. For this series of activities implemented by enterprises for environmental production, auditing departments must audit them strictly and ensure information disclosed by enterprises is sufficient.

2). Whether environmental cost of enterprises is carried out according to accounting policies or not. In auditing process, it is necessary to pay attention to enterprises' accounting policy auditing. Enterprises' accounting policy auditing means related departments audit whether environmental cost accounting is carried out according to environmental policies and laws issued by the country or not. When enterprises implement environmental cost accounting, they will use related environmental policies and laws of the country as accountant arrangement methods of accounting. Environmental cost audit mainly centers on auditing whether enterprises perform environmental cost accounting policies according to related requirements or not and whether enterprises have established effective accounting system in the aspect of environmental cost accounting. Furthermore, it also audits the degree to which enterprises follow system and situations about operation of environmental cost management system.

3). Whether environmental cost accounting is correct and valid or not. When enterprises' environmental cost is audited, we should pay attention to auditing environmental cost accounting to ensure environmental cost accounting of enterprises is standard and reasonable, numerical values are correct and accounting measurement is accurate. Certainly, the said auditing will check accuracy of original data. Especially, it will investigate details of original data. Because environmental cost accounting is carried out artificially, environmental cost audit should check whether environmental cost has been adjusted artificially or not. A number of enterprises often control expenditures of environmental cost to whitewash environmental cost reports to take credits. Therefore, when environmental investigation is carried out, we must audit accounting. Meanwhile, drive enterprises to be more standard and more perfect in accounting via audit.

4). Audit for special enterprises in major projects with pollution. Some enterprises will cause strong pollution for water and air because their production process has specialty. Consequently, we should enhance audit on waste emission standards of such enterprises.

\section{Audit on legality of enterprises' producing activities}

In this thesis, legality of enterprises' producing activities refers to whether enterprises' producing and operating activities accord with national and local laws and regulations about environmental production. The audit on legality of enterprises' producing activities involves auditing departments audit whether enterprises' producing activities accord with related laws. At the same time, what will be audited also contains whether products produced by enterprises meet specified environmental indexes.

To pursue economic benefits and reduce environmental expenditures, many enterprises generate behaviors disobeying environmental rules in their producing and operating activities. Thus, when auditing departments carry out audit, they should pay attention to auditing this phenomenon, estimate enterprises' producing activities and judge whether they have caused bad impacts on environment in their production. The audit emphasis lies in whether enterprises have passed related system certification, whether related environmental devices have been installed and operating situation of such environmental devices.

Whether enterprises' environmental producing activities have obtained according the benefit of environmental protection

With policy support of the national government, more and more enterprises begin to pay attention to their input into environmental cost. Many enterprises enlarge expenditures of environmental cost in producing activities. However, lots of enterprises do not obtain corresponding environmental effect after input. Thus, auditing departments should check whether enterprises perform their responsibility for environmental protection and evaluate whether enterprises' environmental cost 
management has meet corresponding effect or not in time. When effects are investigated, they should pay attention to checking whether enterprises use resources effectively and achieve environmental effect in producing activities, and whether they input energy and work hard for low-carbon operation.

Audit content includes the following aspects; whether funds are wasted in environmental cost, and whether input funds control pollution and improve air and environmental quality. In all, we should pay attention to auditing their environmental benefits when environmental cost of enterprises is audited.

\section{Main points about implementation of audit on enterprises' environmental cost in low-carbon economy}

In accordance with related theories of production, producing activities of an enterprise can be divided into four stages, i.e., product design phase, material preparation phase, product production phase and product sale stage. For various reasons, expenditures of environment cost are needed at each stage. Aiming at the four stages, we need strengthen environmental cost audit of them. Only in this way can we drive enterprises' development and make them realize sustainable development.

\section{Audit at the stage of product design}

Since the stage of product design primarily depends on methods, for instance, computer, expenditures of environmental cost are few. However, the stage of product design need consider making materials of enterprises' producing activities later. Thus, control of environmental cost at the stage of design will reflected by later production. This requires designers should give full consideration to user experience expenditures of environmental cost of products in production and use when they design new products. Based on foregoing aspects, auditing departments should center on whether enterprises involve environmental cost control or not when they audit work at this stage.

\section{Audit at the stage of material preparation}

After finishing product design, the stage of material preparation comes. At this stage, expenditures of environmental cost are mainly reflected by all links like selection and management of materials. Thus, when the stage of material preparation is audited, they following key points should be noticed. First of all, auditing departments should check whether enterprises choose low-carbon and environmental materials when they select materials. Secondly, they should audit whether enterprises carry out reasonable expenditures of environmental cost and perform low-carbon requirements in material management like transportation and storage, and whether enterprises follow environmental purposes in the whole process and meet environmental requirements. At last, auditing department should investigate whether enterprises considers both economic benefit and environmental benefit when they select material suppliers. All of these are key points of the audit at the stage of materials preparation.

\section{Audit at the stage of product production}

At the stage of product production, expenditures of environmental cost occupy most of expenditures of environmental cost in the whole phase. Meanwhile, it is the stage with the largest impact on the whole production link. At the stage of product production, it is essential to control expenditures of environmental cost, adopt a number of low-carbon production technologies, enlarge cleaner production and control emission of production wastes strictly. The audit at the stage of product production should pay attention to possibility of pollution generation before pollution is caused in order to prevent defects of end treatment effectively. In addition, the audit should concentrate on cleaner production and emission of production waste.

\section{Audit at the stage of product sales}

When enterprises provide products for consumers, their products should not only satisfy consumers' demands but also reflect environmental features. As low-carbon thoughts popularizes, an increasing number of consumers pay more attention to environmental properties of products when they implement consumption. Thus, in the auditing process, auditing departments should notice whether products that enterprises provide for consumers reflect have environmental properties or are the ones reflecting environmental properties. When products are sold, auditing departments should 
keep a watchful eye on whether enterprises provide environmental service for consumers, products generate negative impacts on environment in after-sales use and enterprises' products satisfy environmental goals that enterprises make in the beginning or not.

\section{Conclusion}

To sum up, low-carbon economic development cannot be separated from audit on enterprises' environmental cost. Similarly, we can evaluate enterprises' contribution to environmental protection only when we introduce low-carbon economy to audit on enterprises' environmental cost. Enterprises should enhance environmental cost control and auditing departments ought to enhance audit on enterprises' environmental cost. By applying theories about low-carbon economy to audit on enterprises' environmental cost, risks of enterprises' environmental damage can be reduced fundamentally and the outside's supervision related to audit on enterprises' environmental cost can be strengthened simultaneously. Consequently, we should pay attention to enhancing on enterprises' environmental cost in low-carbon economy.

\section{References}

[1] Wei Zhihua. Financial Ecological Environment, Audit Opinion and Debt Financing Cost, Auditing Research, 2012(3).

[2] Yuan Peng. The Construction of the Theoretical Frame of Enterprise Environmental Cost and Management Accounting, Master's Thesis of Lanzhou University of Technology, 2010(6).

[3] Cheng Ting. Overview of Domestic and Foreign Researches on Environmental Auditing, Inquiry into Economic Issues, 2012(11).

[4] Lin Songchi. Discussion on Social Responsibility Audit Based on Low-carbon Economy, Communication of Finance and Accounting, 2013(1).

[5] Wang Xiaoyan. Discussion on Enterprises’ Environmental Cost Control and Evaluation Indexes in Circular Economy, Enterprise Vitality, 2009(3). 